\title{
Expecting Women's Consent for Supervised Medical Student Interventions in Obstetrics and Gynecology
}

\section{Ernesto Gonzalez-Mesa*}

Department of Obstetrics and Gynaecology, Malaga University, School of Medicine, Spain

*Corresponding author: Ernesto Gonzalez-Mesa, Department of Obstetrics and Gynaecology, Malaga University, School of Medicine, Spain; Tel: +34 952131000 ; Email: egonzalezmesa@gmail.com

Rec date: Mar 11, 2014, Acc date: Apr 09, 2014, Pub date: Apr 11, 2014

Copyright: ( 2014 Mesa GE, This is an open-access article distributed under the terms of the Creative Commons Attribution License, which permits unrestricted use, distribution, and reproduction in any medium, provided the original author and source are credited.

\section{Short Communication}

Since the time of Hippocrates, medical training has based itself upon the scientific discoveries of each era, as well as on the roles that doctors have played in each society according to the prevailing beliefs, norms, and social and economic trends of each period. Although the emergence of universities during the Middle Ages allowed for the standardization of medical training to a certain extent, medical training in general and obstetrics and gynecology in particular have frequently been subjects of debate. A doctor's training is undertaken with the purpose of acquiring the necessary theoretical knowledge regarding the different causes of disease, as well as the abilities needed in order to conduct diagnoses and to apply appropriate treatments; in other words, it consists of the theoretical and practical development of medicine.

As a discipline, obstetrics and gynecology are built upon knowledge regarding the physiology, pathology, and treatment of the female genital organs, including the breasts, as well as on aspects related to the normal or abnormal progression of pregnancy, delivery, and the postpartum period.

It is a discipline focused on the study of pathologies related to areas of the body that are frequently subjected to social prejudices and moral connotations of different sorts; this influences its teaching, even due to the prejudices of its own students [1]. It is necessary to reconcile the need to train with patients' right to privacy, and to make a determination regarding the participation of personnel undergoing training in obstetrics or gynecology, which frequently involves the examination of the genital areas [2]. Obtaining consent from patients in order to be examined by students, even when done under general anesthesia, is considered an indispensable ethical requirement, as is evidenced in a variety of fields $[3,4]$. This requirement conditions not only the acquisition of basic competencies within the specialty, but also the way in which the faculty evaluates them. Women's health care professionals have to provide the means so that the environment in which medical procedures take place is favorable to the necessary consent of a patient to a medical student's supervised intervention.

\section{References}

1. Abraham S (1996) The effect of sexual experience on the attitudes of medical students to learning gynecological examinations. J Psychosom Obstet Gynaecol 17: 15-20.

2. Coldicott Y, Pope C, Roberts C (2003) The ethics of intimate examinations-teaching tomorrow's doctors. BMJ 326: 97-101.

3. Broadmore J, Hutton JD, Langdana F (2009) Medical students experience of vaginal examinations of anaesthetised women. BJOG 116: 731-733.

4. Martyn F, O'Connor RA (2009) Medical students' experience of vaginal examinations of anaesthetized women. BJOG 116: 1544-1545.
This article was originally published in a special issue, entitled: "Obstetrics and Gynecology", Edited by Special issue Author Yigit Cakiroglu Department of Obstetrics and Gynecology Kocaeli University Kocaeli, Turkey 